\title{
Full-thickness gastric plication with Overstitch endoscopic suturing device for postsurgical chronic gastroparesis
}

A 28-year-old woman with a past history of dysplastic Barrett's esophagus treated with Ivor Lewis esophagectomy presented with recurrent episodes of dysphagia. Upper gastrointestinal (UGI) series showed delayed gastric emptying with pyloric hypertrophy secondary to postsurgical denervation of the vagal nerve trunks. After multiple unsuccessful endoscopic dilations of the pylorus, the patient underwent a Roux-en-Y gastrojejunostomy with antrum and pylorus exclusion, with resolution of symptoms (> Fig. 1 a).

After 2 years, she developed recurrent postprandial vomiting that did not respond to medical treatment, with consequent progressive weight loss. UGI series showed marked paresis and atony of the remnant conduit stomach, with prolonged transit time and severe stagnation ( $>$ Fig. 1 b, $>$ Fig. 2 ).

To avoid total gastrectomy, the definitive approach in cases of refractory gastroparesis, and considering the possible high peri- or postoperative complications [1], we opted for a full-thickness gastric plication using the OverStitch endoscopic suturing system (Apollo Endosurgery, USA) (\Video 1). Under general anesthesia, we first dissected the mucosal layers of the borders of the atonic gastric area using an O-type HybridKnife (Erbe Electromedizin). Approximating the gastric walls, we excluded the major part of the remnant stomach, markedly reducing the receptive capacity, projecting the liquid/solid nutrients directly to the gastrojejunostomy more rapidly ( Fig. 1 c).

Over the following 9 months, we observed resolution of symptoms and improvement in the kinetics of gastric emptying ( $>$ Fig. 3 ).

Chronic gastroparesis is a motility dysfunction consisting of delayed gastric emptying that occurs in the absence of any identifiable outflow obstruction and does not respond effectively to tradition-

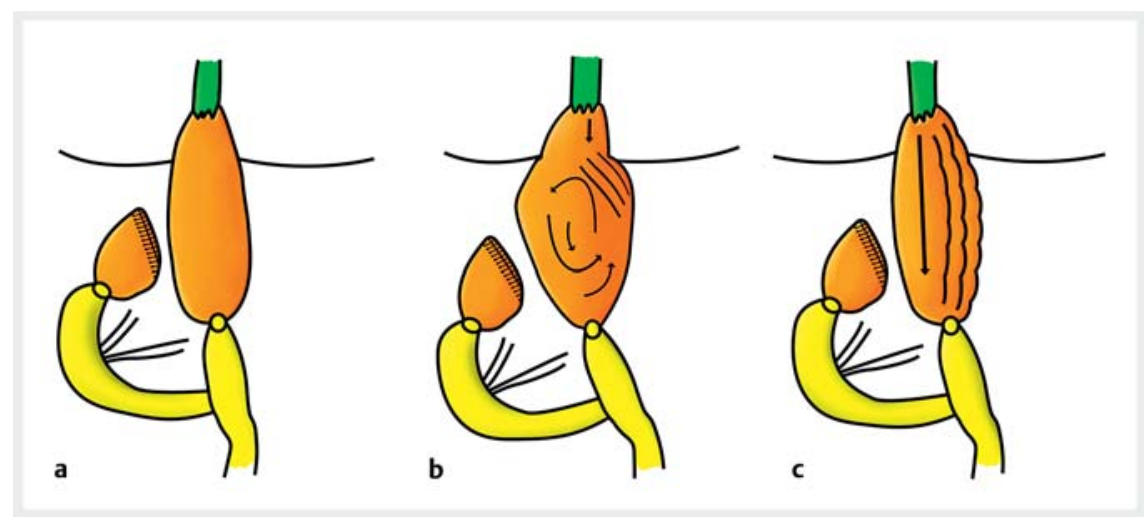

Fig. 1 a Following Ivor Lewis esophagectomy, a Roux-en-Y gastrojejunostomy was performed with preservation of the antrum and pylorus. $\mathbf{b}$ Complete atony of the remnant dilated conduit and severe gastric stagnation impede physiological gastrointestinal transit. c Gastric plication using the endoscopic suturing system allowed plastic tubulization of the remnant stomach with normal emptying. Green, esophagus; orange, stomach; yellow, small intestine. Source: Federico Amata.

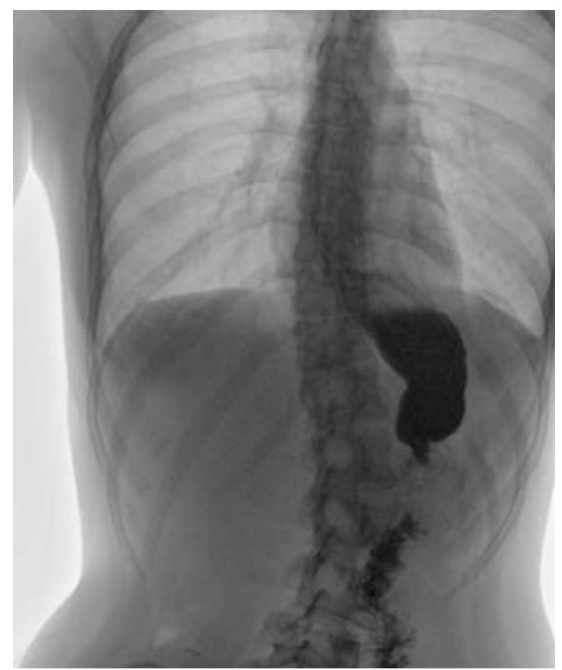

Fig. 2 Barium swallow revealed absence of peristaltic waves of the stomach with atony and severe stagnation of the oral contrast dye.

al treatment [2,3]. Chronic gastroparesis as a postsurgical complication is rare compared to the diabetes mellitus and idiopathic etiologies, but it can occur in cases of gastric resection and/or vagotomy [3,4]. The mini-invasive endoscopic approach described here seems to be a

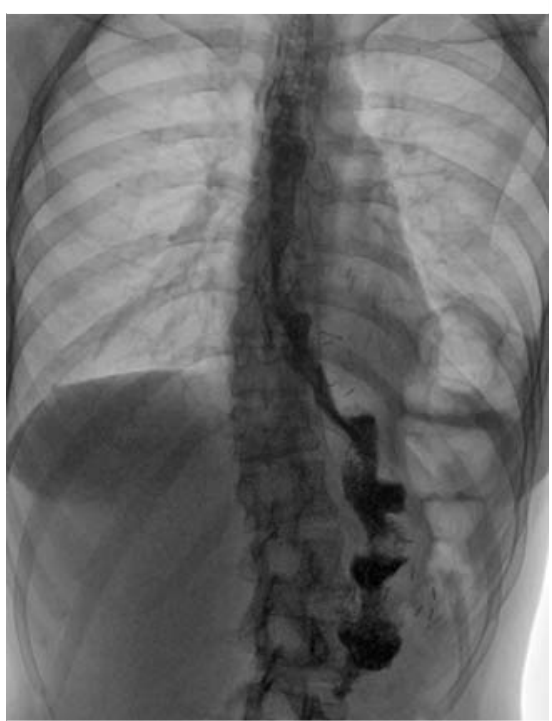

Fig. 3 UGl series at 3-month follow-up showed direct transit of contrast dye into the Roux-en-Y gastrojejunostomy.

valid alternative, particularly in patients with a history of multiple surgical revisions.

Endoscopy_UCTN_Code_TTT_1AO_2AN 


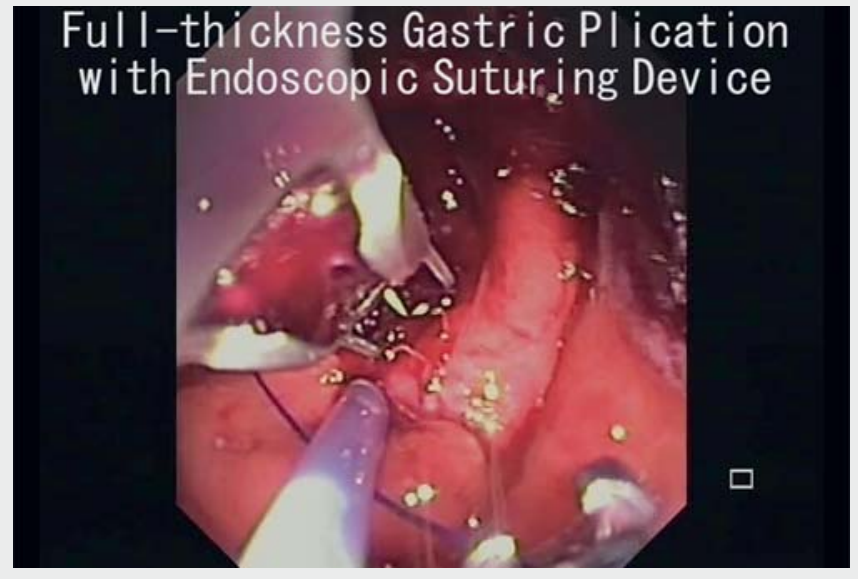

$\checkmark$ Video 1 Postsurgical chronic gastroparesis successfully treated with a novel mini-invasive approach: full-thickness gastric plication using the Overstitch endoscopic suturing system. Source for graphical illustration: Federico Amata.

\section{Acknowledgments}

We thank Federico Amata for graphics assistance.

\section{Competing interests}

The authors declare that they have no conflict of interest.

The authors

Antonino Granata ${ }^{1}$, Michele Amata ${ }^{1}$, Alberto Martino', Lavinia De Monte'2, Alessandro Bertani $^{2}$, Dario Ligresti ${ }^{1}$, Mario Traina ${ }^{1}$

1 IRCCS - ISMETT, Endoscopy Service, Department of Diagnostic and Therapeutic Services, Palermo, Italy

2 IRCCS - ISMETT, Thoracic Surgery, Department for the Treatment and Study of Cardiothoracic Diseases and Cardiothoracic Transplantation, Palermo, Italy

\section{Corresponding author}

\section{Antonino Granata, MD}

Endoscopy Service, IRCCS - ISMETT, Via Tricomi 5, 90127 Palermo, Italy Fax: +39-091-2192400 (specify Endoscopy Service)

agranata@ismett.edu

\section{References}

[1] Landreneau JP, Strong AT, El-Hayek K et al. Gastrectomy versus stomach left in situ with Roux-en-Y reconstruction for the treatment of gastroparesis. Surg Endosc 2019. doi:10.1007/s00464-019-06951-3

[2] Abrahamsson H. Treatment options for patients with severe gastroparesis. Gut 2007; 56: 877-883

[3] Waseem S, Moshiree B, Draganov PV. Gastroparesis: current diagnostic challenges and management considerations. World J Gastroenterol 2009; 15: 25-37

[4] Samuel B, Atiemo K, Cohen P et al. The effect of sleeve gastrectomy on gastroparesis: short clinical review. Bariatr Surg Pract Patient Care 2016; 11: 84-89

\section{Bibliography}

DOI https://doi.org/10.1055/a-1076-0652

Published online: 22.1.2020

Endoscopy 2020; 52: E235-E236

(c) Georg Thieme Verlag KG

Stuttgart · New York

ISSN 0013-726X

\section{ENDOSCOPY E-VIDEOS}

https://eref.thieme.de/e-videos

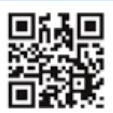

Endoscopy E-Videos is a free access online section, reporting on interesting cases and new

techniques in gastroenterological endoscopy. All papers include a high quality video and all contributions are freely accessible online.

This section has its own submission website at https://mc.manuscriptcentral.com/e-videos 